\title{
Unsupervised classification of saturated areas using a time series of remotely sensed images
}

\author{
D. A. de Alwis ${ }^{1}$, Z. M. Easton ${ }^{1}$, H. E. Dahlke ${ }^{1}$, W. D. Philpot ${ }^{2}$, and T. S. Steenhuis ${ }^{1}$ \\ ${ }^{1}$ Department of Biological and Environmental Engineering, Riley-Robb Hall, Cornell University, Ithaca, NY 14853, USA \\ ${ }^{2}$ School of Civil and Environmental Engineering, Hollister Hall, Cornell University, Ithaca, NY 14853, USA
}

Received: 24 May 2007 - Published in Hydrol. Earth Syst. Sci. Discuss.: 15 June 2007

Revised: 5 September 2007 - Accepted: 11 September 2007 - Published: 27 September 2007

\begin{abstract}
The spatial distribution of saturated areas is an important consideration in numerous applications, such as water resource planning or siting of management practices. However, in humid well vegetated climates where runoff is produced by saturation excess processes on hydrologically active areas (HAA) the delineation of these areas can be difficult and time consuming. A technique that can simply and reliably predict these areas would be a powerful tool for scientists and watershed managers tasked with implementing practices to improve water quality. Remotely sensed data is a source of spatial information and could be used to identify HAAs. This study describes a methodology to determine the spatial variability of saturated areas using a temporal sequence of remotely sensed images. The Normalized Difference Water Index (NDWI) was derived from medium resolution Landsat 7 ETM+ imagery collected over seven months in the Town Brook watershed in the Catskill Mountains of New York State and used to characterize the areas susceptible to saturation. We found that within a single land cover, saturated areas were characterized by the soil surface water content when the vegetation was dormant and leaf water content of the vegetation during the growing season. The resulting HAA map agreed well with both observed and spatially distributed computer simulated saturated areas (accuracies from 49 to $79 \%$ ). This methodology shows that remote sensing can be used to capture temporal variations in vegetation phenology as well as spatial/temporal variation in surface water content, and appears promising for delineating saturated areas in the landscape.
\end{abstract}

Correspondence to: T. S. Steenhuis

(tss1@cornell.edu)

\section{Introduction}

The spatial and temporal distribution of soil moisture is an important parameter to correctly characterize. Numerous applications rely on information about soil moisture levels, from hydrologic and climate models to techniques aimed at optimizing best management practices in agricultural watersheds. Remote sensing techniques can be used to obtain the spatial distribution of the soil moisture content over large areas, reducing expensive and time consuming field measurements.

In the Northeast United States there is great interest in delineating saturated areas that contribute surface runoff and non point source pollutant loads to surface waters. Once these areas are identified, management practices can be developed and implemented to control pollution. The highly permeable surface soils underlain by a dense layer of glacial till cause the majority of the runoff to be produced in areas of the landscape that become saturated either when rainfall exceeds potential evaporation over an extended time or when the groundwater table intersects the soil surface. These saturated or Hydrologically Active Areas (HAA) expand and contract during the course of the year (Dunne and Black, 1970; Dunne and Leopold 1978; Beven, 2001; Needleman et al., 2004), making delineation difficult.

One way of determining soil moisture contents from remotely sensed data is by using the thermal emissions from soils in the microwave range, generally sensitive to moisture variations in the top five centimeters of the soil (Guha and Lakshmi, 2002). Saturated surfaces emit low levels of microwave radiation, whereas dry soils emit much higher levels of microwave radiation (Wang and Schmugge, 1980). However, in many applications it is difficult to separate the microwave signals emitted on saturated and unsaturated soils due to competing effects of moisture content, surface roughness, vegetation, liquid precipitation, and complex topography unless the variables are known a priori (Schmugge,

Published by Copernicus Publications on behalf of the European Geosciences Union. 
1985; Bindlish et al., 2003). Hence, an extensive amount of calibration is necessary to fit the parameters and prior knowledge of the surface cover and state is required (Kerr, 2007). Indeed, Wagner et al. (2007) state that microwave remote sensing systems can capture the general trends in surface soil moisture conditions, but are not appropriate for estimating absolute soil moisture values.

A more promising approach to obtain soil moisture variability is to remotely sense greenness variations of biomass within an otherwise homogeneous canopy (Yang et al., 2006), because variations in soil water directly affect growth patterns of the overlying vegetation. For example, in Kansas, Wang et al. (2001) observed that soil moisture affected remotely sensed Normalized Difference Vegetation Index (NDVI) greenness patterns in the Konza Prairie. Vegetation indices such as the NDVI make use of the contrast between the strong reflection of vegetation in the near infra-red (NIR) and the strong absorption by chlorophyll in the red (R) (Gates et al., 1965). However, one disadvantage of the vegetation indices is that they are only sensitive to biomass in the early growth stages when the leaf area index is less than three (Cohen et al., 2003; Friedl et al., 1994; Law and Waring, 1994; Chen and Chilar; Fassnacht et al., 1997). Above three, there is no clear relationship between biomass and vegetation indices (Fassnacht et al., 1997; Killelea, 2005). Another potential disadvantage when relating moisture content and vegetation indices is that vegetation growth is dependent upon a number of environmental factors, such as nutrient availability, disease pressure, insect infestation, temperature, wind, soil moisture content, and relative humidity. It is important not to misinterpret changes in vegetation growth patterns as related solely to soil wetness. Nonetheless, there is clear evidence that hydrologic properties can have a strong effect on vegetation growth (De Jong et al., 1984; Farrar et al., 1994; Nicholson and Farrar, 1994; Timlin et al., 2001).

Similar to vegetation indices but more sensitive to moisture contents at the near surface are indices using measurements in the short-wave infrared (SWIR) band, where strong water absorption bands are centered around 1450, 1500 and $1950 \mathrm{~nm}$ (Karnieli et al., 2001). Since virtually no light penetrates the atmosphere near the center of these bands, the bands selected for satellite sensors are typically chosen to avoid them. However, the absorption bands are quite broad, and still have an influence well away from the center wavelengths. The feasibility of using the SWIR bands was first suggested by Tucker (1980) who noted that Landsat 7 ETM+ Band 5, and the SWIR band of MODIS (1550 to $1750 \mathrm{~nm}$ ) would be well suited for remote sensing of the plant canopy water content. While this band will also be sensitive to variations in atmospheric water vapor, over relatively small areas and on clear days, the atmospheric variability will generally be negligible and the local variations will be related to the presence of water on the land surface. In vegetated areas, absorption by leaf water occurs in the SWIR and the reflectance from plants thereby is negatively related to the leaf water content (Ceccato, et al., 2001; Hunt et al., 1987; Tucker, 1980). In the absence of vegetative cover, the local variations in Landsat 7 ETM+ Band 5 reflectance will be sensitive to changes in the surface (near surface) soil moisture content (Whiting et al., 2004; Xiao et al., 2002), while for plants it will sense the water content in the vegetation.

Variations in reflectance may also occur due to variations in internal leaf structure, leaf dry matter content (Fensholt, 2004), soil mineral composition, and organic matter content (Whiting et al., 2004). Consequently, Landsat 7 ETM+ Band 5 reflectance values alone are not suitable for retrieving vegetation water content. In the NIR (Landsat 7 ETM+ Band 4, 780-900 nm), well away from the water absorption band, reflectance is influenced most by the same factors affecting the Landsat 7 ETM+ Band 5 or SWIR band (e.g. leaf internal structure and leaf dry matter content), but not by water content (Fensholt, 2004). By considering information from both the Landsat 7 ETM+ Bands 4 and 5 we can obtain a better estimate of the true moisture status. The Normalized Difference Water Index, NDWI, (Gao, 1996) has been proposed to exploit this characteristic of Bands 4 and 5. Another advantage of using NDWI, as opposed to the NDVI, is that saturation does not occur until a Leaf Area Index (LAI) of six or greater (Fensholt, 2004).

Once the values for NDWI are obtained, there are two approaches to aggregating pixels of land cover into homogeneous regions of wetness behavior: supervised and unsupervised classification. Supervised classification relies on the expertise of the analyst to define training sites using prior knowledge of the site but can be labor intensive (Foody and Arora, 1996). In unsupervised classification, pixels that exhibit similar characteristics are subdivided into homogeneous spectral regions based on a set of boundary conditions specified by the user (Le Hegarat-Mascle et al., 1997). Once the homogeneous regions are classified, knowledge of the area under study is needed to assign the correct wetness index to each region. Both supervised and unsupervised classifications require the user to possess knowledge of the study area in order to complete the classification. However, the clustering portion of unsupervised classification operates without a priori information of the wetness index classification and groups samples based on the inherent similarity of individual NDWI time classes.

The objective of this study is to test the ability of remote sensing techniques, specifically the NDWI derived from Landsat 7 ETM+ measurements for obtaining the spatial distribution of frequently saturated areas in the landscape that contribute the majority of the runoff and water-born pollutants during storm events. We first separate the landscape into different land cover types and then relate the temporal NDWI pattern within each land cover type to the soil moisture status. The hydrology of the region is such that in late fall, winter, and early spring saturated areas develop mostly in the lower areas of the watershed on concave slopes and at locations where flatter slopes reduce the hydraulic gradient. 


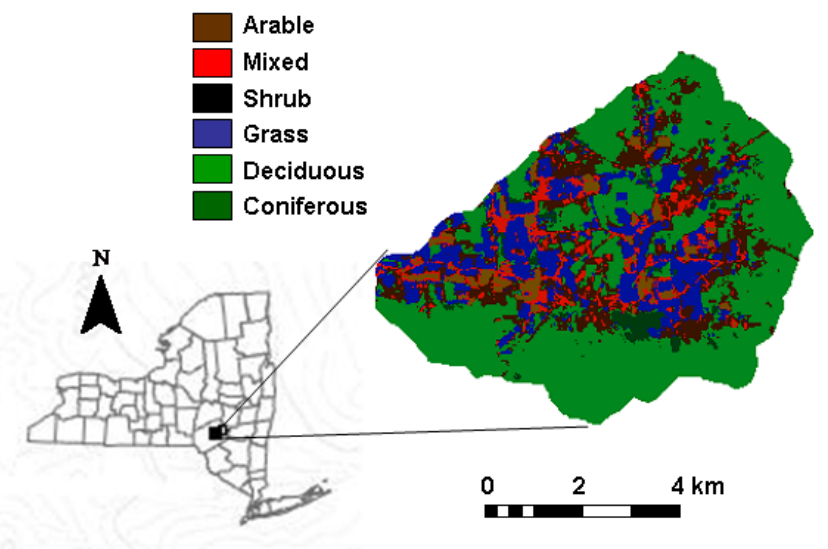

Fig. 1. Land cover in the Town Brook watershed (de Alwis, 2007). Inset figure gives the location of the Town Brook watershed in New York State.

We hypothesize that areas of the landscape prone to saturated conditions will exhibit higher NDWI in the spring, particularly following snowmelt. These areas typically have less soil storage capacity, and drain large areas making them saturate more frequently. Thus, during the typically drier summer months we expect these areas to dry out more rapidly due to the lower soil storage capacity and the cessation of interflow from upslope, and maintain a lower NDWI than areas of the landscape more conducive to plant growth (i.e., areas with greater soil storage capacity and more plant available water). We then assess the accuracy of the NDWI predictions using several techniques, including ground truth data collected in the watershed, as well as by comparison with two distributed hydrologic models.

\section{Methods}

\subsection{Study site}

The site for this study was the Town Brook watershed (Fig. 1), in the Catskill Mountain region in New York State. The Town Brook watershed has an area of $37 \mathrm{~km}^{2}$ and an elevation range of 511 to $989 \mathrm{~m}$ (Fig. 2). The underlying geology of the watershed was formed during the glacial period, the north facing slopes are generally steep with shallow soils overlaying a dense glacial till and fractured bedrock covered mostly in deciduous and coniferous forests. The south facing slopes are gentler with deeper soils particularly in the lower slope regions and are covered by shrubs, pastures, alfalfa, and corn grown in rotation.

\subsection{Satellite images}

A time sequence of multi-spectral Landsat 7 ETM+ images was used to identify spatial/temporal changes in the vegetative cover of Town Brook. The Landsat 7 ETM+ creates

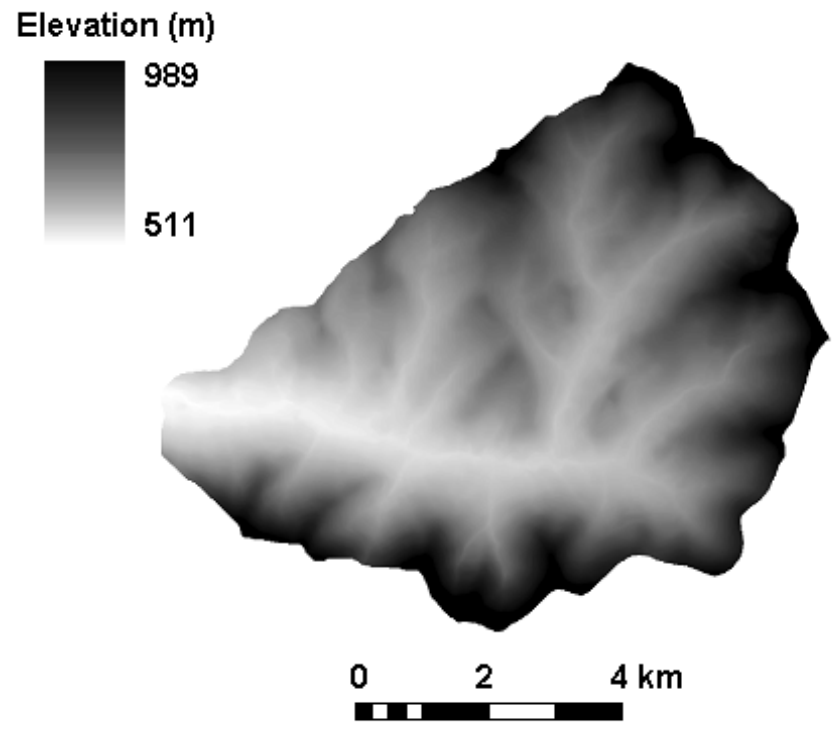

Fig. 2. Digital elevation model of the Town Brook watershed.

images with $30 \mathrm{~m} \times 30 \mathrm{~m}$ pixel size. The satellite orbital profile operates on a 16-day cycle, with each image covering a swath $183 \mathrm{~km}$ wide. The spectral range of Band 4 is 780 $900 \mathrm{~nm}$, and is primarily used to estimate biomass, although it can also discriminate water bodies, and soil moisture from vegetation. Band 5 has a spectral range of $1550-1750 \mathrm{~nm}$, and is particularly responsive variations in biomass and moisture. Seven cloud-free images were obtained on the following dates: 27 January 2000, 5 April 2001, 7 May 2001, 8 June 2001, 10 July 2001, 12 September 2001, and 30 October 2001. The vegetation and water indices calculated from these images are dependent on precipitation and snow cover on the ground. When the January 2000 image was taken there was snow on the ground. During the rest of the acquisition period in 2001 there was $85 \mathrm{~cm}$ of precipitation, which is below the thirty year average of $102 \mathrm{~cm}$ measured at Delhi, NY, located $20 \mathrm{~km}$ west of Town Brook watershed. Only March 2001 and October 2001 had precipitation in excess of the 30 year average. The snow that fell in March 2001 had almost melted by 5 April 2001 when the satellite image was taken, and the May image was taken after a two-week period without precipitation. The seven images were used to create the NDWI for the analysis.

\subsection{Calculation of NDWI and NDVI}

In analogy to the procedure proposed for the MODIS system by Fensholt (2004), the NDWI based on Landsat 7 ETM+ Bands 4 and 5 is defined as follows for each of the seven images:

$\mathrm{NDWI}=\frac{\rho_{(780-900 \mathrm{~nm})}-\rho_{(1550-1750 \mathrm{~nm})}}{\rho_{(780-900 \mathrm{~nm})}+\rho_{(1550-1750 \mathrm{~nm})}}$ 
Table 1. Parameter set used in the ISODATA analysis.

\begin{tabular}{ll}
\hline Number of classes & 2 to 3 \\
Maximum iterations & 1000 \\
Change threshold & $1 \%$ \\
Minimum pixels in class & 5 \\
Maximum standard deviation in digital counts & 15 \\
Minimum class distance in digital counts & 25 \\
Maximum distance error in digital counts & 160 \\
\hline
\end{tabular}

where $\rho_{(780-900 \mathrm{~nm})}$ is the reflectance in Band 4 of Landsat 7 ETM+, the near infrared band and $\rho_{(1550-1750 \mathrm{~nm})}$ is the reflectance in Band 5 of Landsat 7 ETM+, the middle infrared band.

Similarly the normalized difference vegetation index (NDVI) that employs the reflectance in Band 4, is defined for the seven images as (Richardson et al., 1992):

$\mathrm{NDVI}=\frac{\rho_{(780-900 \mathrm{~nm})}-\rho_{(630-690 \mathrm{~nm})}}{\rho_{(780-900 \mathrm{~nm})}+\rho_{(630-690 \mathrm{~nm})}}$

where $\rho_{(630-690 \mathrm{~nm})}$ is the reflectance in Band 3 of Landsat 7 ETM+, the red band and $\rho(780-900 \mathrm{~nm})$ is the reflectance in Band 4 of Landsat 7 ETM+, the near infrared band.

The NDWI and NDVI are defined in terms of reflectance at the surface while Landsat $7 \mathrm{ETM}+$ measurements are in terms of radiance measured at the satellite, a value that includes the radiance from the atmosphere including light reaching the sensor, scattering and absorption by gasses, water vapor, and aerosols (Song et al., 2001). Because of the difficulty of performing an atmospheric correction, it is common practice to use radiance at the detector (after correction for path radiance) instead of reflectance of the target at the surface (Lu et al., 2002; Song et al., 2001). We corrected for path radiance using a dark object subtraction (DOS) correction by calculating the average signal over water bodies for the red and infrared bands and subtracting it from the respective red and infrared bands of the entire scene in order to adjust for the atmospheric path radiance. The DOS is the single most important adjustment needed to make the NDWI and NDVI usable when comparing a time sequence of images.

\subsection{Unsupervised clustering of NDWI}

The three main unsupervised clustering algorithms are $\mathrm{K}$ means, Iterative Self Organized Data Analysis Technique A (ISODATA) and the Automatic Classification of Time Series (ACTS) (Tou and Gonzalez, 1972; Viovy, 2000; de Alwis, 2007). In an unsupervised classification, statistical clustering algorithms are used to analyze the digital values in a stack of imagery to determine the number of statistically distinct features (clusters) in the imagery. In this study, an unsupervised ISODATA (ENVI, Research Systems Inc. 2002) clustering algorithm was used. The ISODATA algorithm is a widely used clustering algorithm that makes a large number of passes through an image using a minimum spectral distance formula to form clusters. It begins with arbitrary cluster means and each time the clustering repeats the means of these clusters are shifted. The new cluster means are used for the next iteration. This iterative process continues until statistically distinct features emerge. The ISODATA technique allows the user to specify the number of classes the data is separated into for clustering within each land cover. The statistical thresholds used to separate the classes in the ISODATA analysis are shown in Table 1.

The land cover map used for this study was obtained by analyzing the temporal behavior of vegetation greenness from vegetation indices (NDVI) derived from the same seven images to segregate and identify vegetation with no prior information about the area (de Alwis, 2007). The images were used to identify spatial differences and temporal changes that occurred due to the phenological cycle of vegetative cover over the study site. By analyzing the variations in the NDVI of clusters of pixels over time phenological patterns were obtained and distinctive land cover types were identified accordingly. The obtained land cover map was validated using ground truth and air borne imagery. The land cover map based on the phenological variations proved to be better than the available land cover map derived based on spectral classification (de Alwis, 2007). The land cover map based on phenology was able to distinguish the shadowed areas that are often misclassified as evergreen in spectral classification. This was a major advantage of using a classification based on phenology rather than a spectral based classification. Land cover types determined using phenology were arable land, grass/pasture, shrub, deciduous forest, coniferous forest, and mixed forest (Fig. 1). Using masks of each of the land cover types, an image cube or stack was then created for the seven DOS corrected NDWI images. The initial NDWI values that varied from -1 to +1 were linearly stretched between zero and 255 by assigning the least NDWI value in each image cube a value of zero and the maximum NDWI a value of 255 . The stretch was necessary because the ISODATA clustering algorithm operates only on integer values. The ISODATA technique divided the NDWI values of the image cubes for each land cover type into two or three NDWI regions with significantly different temporal patterns based on the parameter thresholds for clustering shown in Table 1. The pattern in NDWI values for the regions represents the temporal variation of surface soil moisture (before leaf on) and leaf water content during the growing season.

\subsection{Identification of hydrologically active areas (HAA)}

Next we related the NDWI patterns within each land cover to the HAAs in the Town Brook watershed. Town Brook has shallow, highly conductive soils with depths of 30 to $140 \mathrm{~cm}$ over a restrictive hardpan. Lateral flow in the shallow surface 

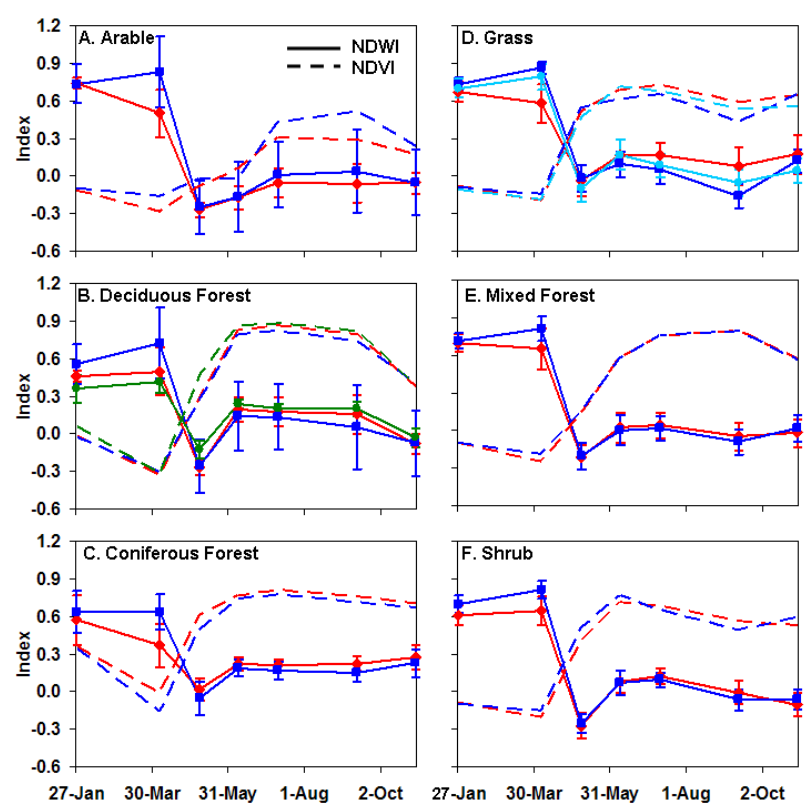

Fig. 3. Variation of the Normalized Difference in Water Index (NDWI) of the two to three homogeneous regions in each of the land cover types (as defined by ISODATA analysis for (a) Arable land, (b) Deciduous Forests (c) Coniferous Forests (d) Grass/Pasture, (e) Mixed Forests, (f) Shrub. Blue lines in all figures show the NDWI for predicted saturated zones, red lines show the NDWI for predicted unsaturated zones, in grass/pasture and deciduous forest the light blue and green lines show the NDWI for zones of intermediate saturation. Shown for comparative purposes is the Normalized Difference in Vegetation Index (NDVI) corresponding to each NDWI series.

soil occurs during periods when the precipitation exceeds the potential evaporation and tends to form a saturated area at the bottom of slopes or areas with shallow soils where the storage is exceeded. These HAAs saturate during rainfall events and produce runoff. During the period when potential evapotranspiration exceeds rainfall, the soils dry; interflow drains the water from the soil profile and most of the HAAs dry up and can, in fact, dry out more than other soils in the watershed that are deeper and have a greater storage capacity. During the period when precipitation exceeds evapotranspiration we hypothesize that HAA will be detectable on these low storage, shallow soils underlain by a restricting layer. Intuitively, these same areas that saturate during the period when precipitation is greater than evapotranspiration (due to interflow from upslope areas) will be drier during the period where evapotranspiration exceeds precipitation when interflow stops (and have lower NDWI values) (Fig. 3). Similarly, regions that had low NDWI during early growing season and high NDWI due to high leaf water content during the growing season are regions with a low propensity to saturate for prolonged periods as indicated by the better vegetative growth conditions (Fig. 3). The NDWI predicted saturated areas are shown in Fig. 4.

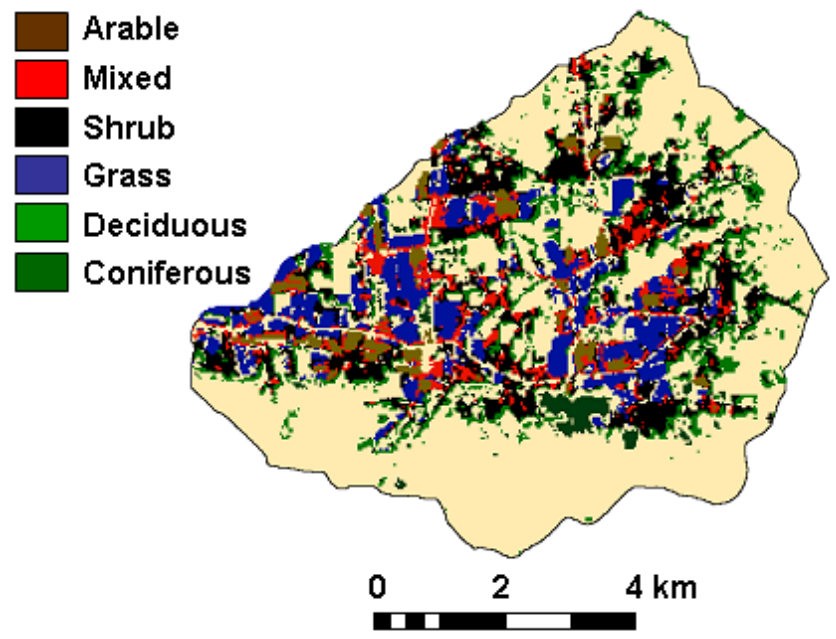

Fig. 4. Normalized Difference in Water Index (NDWI) predicted saturated (wet) areas for each of the land cover types (Arable land, Mixed Forests, Shrub, Grass/Pasture, Deciduous Forests, and Coniferous Forest).

\subsection{Accuracy assessment}

Little spatially distributed data on the soil moisture content is readily available; therefore, we propose several ways of testing the results: corroboration with existing hydrologic models and a field survey of saturated areas in the watershed. The remotely sensed HAAs were compared with the distributed output of two simulation models developed for watersheds such as Town Brook, specifically, the Soil Moisture Distribution and Routing (SMDR) model (Frankenberger et al., 1999) and Variable Source Loading Function (VSLF) model (Schneiderman et al., 2007). We also used a field survey in the upper reaches of the watershed conducted in 2006 to identify frequently saturated areas. While the simulation models results by no means represent the absolute ground truth we have selected two models that have been shown to capture the evolution of HAAs in the landscape, and should provide an adequate representation of saturated areas. Models based on topographic indices, such as VSLF, or more mechanistic models such as the Soil Moisture Distribution and Routing model (SMDR) (Zollweg et al., 1996; Frankenberger et al., 1999) are two modeling concepts with modest input requirements capable of capturing the spatial distribution of soil moisture levels at the watershed scale. Both models have been shown to identify saturated areas, albeit for different types of systems. Topographic index based models generally assume that a watershed wide water table intersects the landscape to produce saturated runoff generating areas and SMDR assumes that these areas are controlled by transient interflow perched on a shallow restricting layer.

The Soil Moisture Distribution and Routing (SMDR) model is a physically-based, fully-distributed model that simulates the hydrology for watersheds with shallow sloping 
soils. The model was developed specifically for regions such as Town Brook (Frankenberger et al., 1999). The model combines elevation, soil, and land use data, to predict the spatial distribution of soil moisture, evapotranspiration, saturationexcess overland flow (i.e., surface runoff), and interflow throughout a watershed on a daily time step. Soil moisture content is predicted for each cell, typically of dimension $10 \mathrm{~m}$. SMDR has been extensively validated in Town Brook (Mehta et al., 2004), and other basins in the region (e.g. Frankenberger et al., 1999; Hively et al., 2005; Easton et al., 2007: more information at http://soilandwater.bee. cornell.edu/).

The Variable Source Loading Function (VSLF) model (Schneiderman et al., 2007), a derivative of the Generalized Watershed Loading Function (GWLF) model (Haith and Shoemaker, 1987), uses the Soil Conservation Curve Number (SCS-CN) (USDA-SCS, 1972) method to predict runoff. The main difference between the VSLF and GWLF approaches to using the SCS runoff equation is that runoff is explicitly attributable to source areas according to a soil topographic index distribution rather than by land use and soil type as in original GWLF. Runoff and soil moisture are then distributed throughout the watershed according to a spatially weighted soil topographic index (Lyon et al., 2004) VSLF has been used in the Catskill Mountains to predict hydrology and water quality, and has been validated spatially to predict saturated areas (Schneiderman et al., 2007).

The remotely sensed saturated areas were also compared with a field survey of saturated areas. The field survey was conducted in spring 2006 during the period when HAAs would be most saturated, and should compare reasonably well with HAAs derived by the NDWI. In order to validate the remotely sensed saturated areas the producer's and user's accuracies were calculated for comparisons with simulated data and field surveys. The producer's accuracy for a saturated area within a land cover type is defined as the probability within a land cover type that a pixel truly belonging to a saturated area within a land cover type is also mapped as a saturated area within the land cover type, while the user's accuracy for a saturated area within a land cover type is the probability that a pixel mapped as a saturated area is truly of a saturated area.

\section{Results}

An average value of NDWI for each of the seven Landsat 7 ETM+ images for the different months was obtained for each of the temporally homogeneous NDWI regions that were identified by the ISODATA clustering method within each of the six land cover types (Table 1). These average NDWI values for the wetness classes are depicted in Fig. 3.

The NDWI time series plots (Fig. 3) show the seasonal dynamics within and between land cover types. The NDWI for all land covers is elevated in January and April when the soil is wet. The lowest NDWI occurred in May after a 15 day dry period reduced the moisture content of the soil surface. The NDWI values increase subsequently for June and July due to the increase in leaf water content. The NDWI values for the deciduous and mixed forest decrease at the end in October (due to leaf senescence). The NDWI for the shrub, coniferous forest, and arable land covers remain stable through the fall, while grass/pasture increase marginally. The slight increase in the NDWI for the grass/pasture is likely due to continued biomass accumulation into the fall, presumably increasing the leaf water content.

Comparing the NDWI curves of deciduous forests, grass, shrub, mixed forests, arable land and coniferous forests land cover types in Fig. 3 it is evident that there is a region among all land cover types that is more wet (high NDWI) in the spring than the other homogeneous regions and drier (low NDWI) late in the growing season. This characteristic is consistent among all the land cover types. This region is shown in blue in Fig. 3 and, according to our hypothesis, is identified as the wet region in the land cover type. Regions within a land cover type having low surface water content during the early growing season and more leaf water content during the late growing season were identified as dry areas that were favorable for plant growth (due to high leaf water content during the late growing season).

Figure 3 shows the greatest variation in NDWI values between March and April 2001, where snow cover went from $20 \mathrm{~cm}$ in March to essentially zero in April. The NDWI is high due to the snow cover and the increase in surface soil moisture from snowmelt. At the same time the evapotranspiration loss was small and we expected that the HAAs were fully saturated. The result is that during the early growing season the areas with shallow soil, a high water table, or a large contributing area tended to saturate and were captured in the NDWI images. During the summer when evapotranspiration exceeds rainfall and interflow supplying water from upslope to the HAAs ceases the differences in NDWI values decreases substantially (Fig. 3). During May and June it is reasonable to assume that the increase in the NDWI in most land covers is due to the increase in biomass, and subsequent leaf water content from maturing vegetation. During the summer, it is of interest to note that the moisture content in the HAAs that were saturated during the spring snowmelt decreases below that of the remaining land cover types (Fig. 3) because the HAA soils are shallower and have less storage.

As a matter of interest, the NDVI values are also calculated for the NDWI wetness classes and show the opposite behavior from that of the NDWI. The NDVI values are low in January and March when there is little biomass and then increase during the rest of the year when plant growth resumes. Detailed information on the differences in NDVI values between land cover types can be found in de Alwis (2007). What is important here is that the different wetness index classes showed few differences in NDVI values. 
Table 2. Producers (PA) and Users Accuracy (UA) assessment of remotely sensed saturated areas compared to the equivalent areal extent by land cover of saturated areas predicted using the Soil Moisture Distribution and Routing (SMDR) model and the Variable Source Loading Function (VSLF) model. The SMDR and VSLF areas are considered ground truth for the classification comparison. Also shown is the accuracy assessment comparison for the two models. Since both models are considered ground truth in this assessment the overall accuracy is not considered.

\begin{tabular}{|c|c|c|c|c|c|}
\hline Land cover & SMDR wet & NDWI wet & Overlap & PA & UA \\
\hline Deciduous forest & 1111 & 3783 & 834 & 0.75 & 0.22 \\
\hline Grass & 5150 & 4170 & 3626 & 0.70 & 0.87 \\
\hline Shrub & 7196 & 6139 & 5758 & 0.80 & 0.94 \\
\hline Mixed forest & 2796 & 2378 & 2349 & 0.84 & 0.99 \\
\hline Arable land & 1378 & 1255 & 1240 & 0.90 & 0.99 \\
\hline Coniferous forest & 341 & 721 & 141 & 0.41 & 0.20 \\
\hline Total & 17972 & 18446 & 13948 & & \\
\hline \multirow[t]{2}{*}{ Overall accuracy } & & & & \multicolumn{2}{|c|}{0.78} \\
\hline & VSLF wet & NDWI wet & Overlap & $\mathrm{PA}$ & UA \\
\hline Deciduous forest & 1723 & 3783 & 1522 & 0.88 & 0.40 \\
\hline Grass & 3889 & 4170 & 2632 & 0.68 & 0.63 \\
\hline Shrub & 7320 & 6139 & 5883 & 0.80 & 0.96 \\
\hline Mixed forest & 2776 & 2378 & 2337 & 0.84 & 0.98 \\
\hline Arable land & 1365 & 1255 & 1244 & 0.91 & 0.99 \\
\hline Coniferous forest & 1041 & 721 & 703 & 0.68 & 0.98 \\
\hline Total & 18114 & 18446 & 14321 & \multirow{2}{*}{\multicolumn{2}{|c|}{0.79}} \\
\hline \multirow[t]{2}{*}{ Overall accuracy } & & & & & \\
\hline & VSLF wet & SMDR wet & Overlap & PA & UA \\
\hline Deciduous forest & 1723 & 1111 & 1063 & 0.62 & 0.96 \\
\hline Grass & 3889 & 5150 & 3087 & 0.79 & 0.60 \\
\hline Shrub & 7320 & 7196 & 6865 & 0.94 & 0.95 \\
\hline Mixed forest & 2776 & 2796 & 2744 & 0.99 & 0.98 \\
\hline Arable land & 1365 & 1378 & 1363 & 1.00 & 0.99 \\
\hline Coniferous forest & 1041 & 341 & 141 & 0.14 & 0.41 \\
\hline Total & 18114 & 17972 & 15263 & & \\
\hline
\end{tabular}

During January and April when there is little biomass (except for coniferous forest), the NDVI values should be the same. During the summer the leaf area index for all land covers is greater than three and it is difficult to discriminate among differences in the NDVI signal. The insensitivity to moisture content makes the NDVI signal a good proxy to distinguish land cover types but a poor predictor of moisture status.

\subsection{Validation}

The main difficulty in comparing the NDWI predicted HAAs is that the remotely sensed saturated areas are static in time and represent an average saturation risk for the year of observation while the saturated areas predicted by SMDR and VSLF are continuous, and dynamic in time. That being said, the NDWI saturated areas should represent areas of the landscape most prone to frequent saturation. To compare the temporally dynamic prediction made by SMDR and VSLF we aggregated predictions during the spring for SMDR and VSLF (March-June 2001), which represents the most prob- able saturated period in this region. The simulated saturation degree maps for SMDR and VSLF were stacked and an average saturation degree was calculated for each of the $10 \mathrm{~m} \times 10 \mathrm{~m}$ pixels. We resampled the $30 \mathrm{~m} \times 30 \mathrm{~m}$ NDWI pixels to $10 \mathrm{~m} \times 10 \mathrm{~m}$ pixel size to compare among models. The area of each specific land cover in Town Brook was calculated and a ratio of total land cover to NDWI saturated area was derived. For example, deciduous forest covers 21677 pixels of Town Brook, of which 3183 are predicted as saturated by the NDWI, that is, $17.5 \%$ of the deciduous forest in Town Brook is predicted as an HAA. Then these areas were extracted independently for each land cover from the SMDR or VSLF saturation degree maps. We assume that the pixels from the SMDR and VSLF maps with the highest saturation degree, corresponding to the fraction of the remotely sensed land cover that was saturated, should theoretically correspond with the remotely sensed data (the $17.5 \%$ of cells with the highest saturation degree for deciduous forest from SMDR and VSLF). This allowed comparison of the potentially saturated areas on an areal basis. 
A. VSLF Predicted Wet Areas

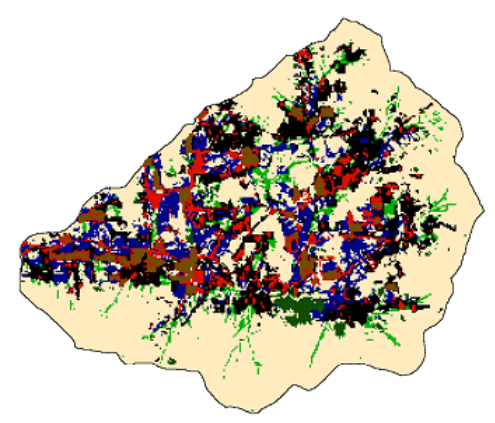

B. NDWI Intersect with VSLF Wet Areas

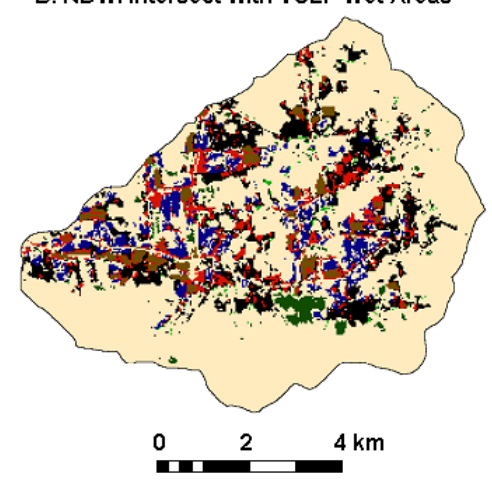

C. SMDR Predicted Wet Areas

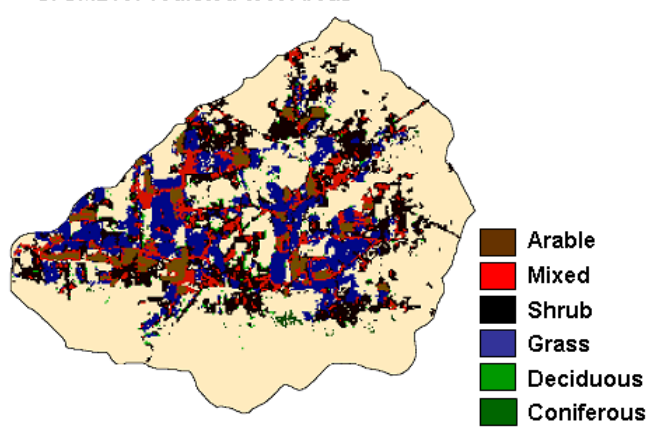

D. NDWI Intersect with SMDR Wet Areas

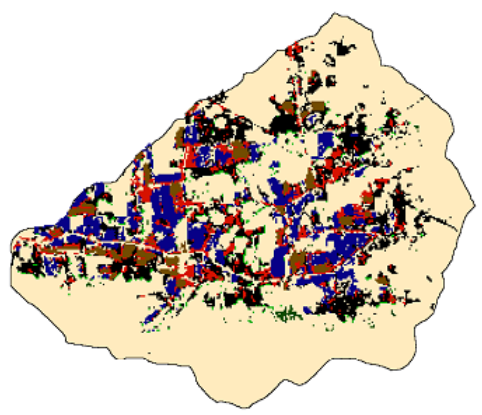

Fig. 5. (a) Saturated areas by land cover predicted by the Variable Source Loading Function (VSLF) model: (b) Intersection of saturated areas predicted by the NDWI and those predicted by VSLF: (c) saturated areas by land cover predicted by the Soil Moisture Distribution and Routing (SMDR) model: (d) Intersection of saturated areas predicted by the NDWI and those predicted by SMDR.

The region maps representing the temporally homogeneous NDWI regions for each land cover type were overlaid on the saturation degree map and the mean saturation degree value within each of the regions was calculated. Results of this comparison are shown in Table 2. In all of the land cover types (except coniferous forests) it seems that the common characteristic of the homogeneous regions that are wet (represented by the blue curves in Fig. 3) in the early growing season and dry in the late growing season have higher saturation degrees than those areas predicted as dry. The remotely sensed saturated areas are shown in Fig. 4. The intersection of the NDWI saturated areas and the SMDR and VSLF saturated areas are shown in Fig. 5. The extent of the remotely sensed NDWI based saturated area predictions for the arable land, deciduous forest, mixed forest, and shrub were extracted from the GIS and the producer (error of omission) and users (error of commission) accuracy were tabulated. Thus, we have a measure of where the remotely sensed NDWI saturated areas agree with the SMDR or VSLF saturated areas (producers' accuracy Table 2). The remotely sensed saturated areas generally agree well with the model predictions with overall accuracies of 0.78 and 0.79 for SMDR and VSLF, respectively. However, saturated areas in the deciduous forest land cover predicted by the remote sensing method do not agree as well with SMDR and VSLF
(Fig. 5, Table 2). The positions of the NDWI saturated areas within the deciduous forests were accurately predicted (producer's accuracy, Table 2) but their extent was over predicted compared to the modeled saturated areas (user's accuracy, Table 2). The main discrepancy between the NDWI saturated areas and the modeled saturated areas is likely that the LAI is greater than six in the forest and the NDWI becomes saturated and unable to discriminate saturated areas. Additionally, the moisture status of the soil surface likely has limited influence on the water content of the deciduous trees, as they can derive water from deeper in the soil, and the leaf water status may be more affected by regional groundwater dynamics then surface phenomena.

To test the above hypothesis further the SMDR and VSLF predicted saturation degree were compared to the remotely sensed homogeneous regions (Table 3). According to the hypothesis within a land cover type a higher surface water content during the early growing season and lower leaf water content during the late growing season indicates a hydrologically sensitive (saturated) area, that are not favorable for plant growth (represented by the blue curve in Fig. 3). Indeed, NDWI predicted saturated areas had a higher soil moisture level as predicted by SMDR and VSLF (Table 3).

Due to the uncertainty inherent in the spatial predictions of any model we conducted a field survey of saturated areas in 
Table 3. Mean saturation degree for the Soil Moisture Distribution and Routing model (SMDR) and the Variable Source Loading Function model (VSLF) for the Normalized Difference in Water Index (NDWI) homogeneous regions in each of the vegetation types. The Region Colors represent the colors used to plot the temporal behavior of the respective regions in Fig. 3. The region color blue represents Normalized Difference in Water Index (NDWI) predicted as saturated (wet) areas for each of the land cover types.

\begin{tabular}{lccc}
\hline Land cover & $\begin{array}{c}\text { Region } \\
\text { color }\end{array}$ & $\begin{array}{c}\text { SMDR } \\
\text { saturation degree }\end{array}$ & $\begin{array}{c}\text { VSLF } \\
\text { saturation degree }\end{array}$ \\
\hline \multirow{2}{*}{ Deciduous forest } & Blue & 0.70 & 0.68 \\
& Green & 0.59 & 0.56 \\
Grass & Red & 0.51 & 0.34 \\
& Blue & 0.65 & 0.71 \\
Shrub & Cyan & 0.56 & 0.53 \\
Mixed forest & Red & 0.36 & 0.47 \\
\multirow{2}{*}{ Arable land } & Blue & 0.57 & 0.65 \\
& Red & 0.34 & 0.36 \\
Coniferous Forest & Blue & 0.62 & 0.67 \\
& Red & 0.39 & 0.39 \\
& Blue & 0.60 & 0.69 \\
& Red & 0.45 & 0.41 \\
& Blue & 0.28 & 0.51 \\
& Red & 0.28 & 0.54 \\
\hline
\end{tabular}

Table 4. Producers (PA) and Users Accuracy (UA) assessment of remotely sensed saturated areas compared to the equivalent areal extent by land cover of saturated areas mapped using a Garmin GPS (GPSmap 60C). The mapped saturation areas are considered ground truth for the classification comparison.

\begin{tabular}{lccccc}
\hline Land cover & Mapping wet & NDWI wet & Overlap & PA & UA \\
\hline Deciduous forest & 242 & 214 & 103 & 0.43 & 0.48 \\
Grass & 67 & 195 & 48 & 0.72 & 0.25 \\
Shrub & 266 & 185 & 132 & 0.5 & 0.71 \\
Mixed forest & 13 & 39 & 11 & 0.85 & 0.28 \\
Arable land & 0 & 2 & 0 & 0 & 0 \\
Coniferous forest & 61 & 111 & 21 & 0.34 & 0.19 \\
Total & 649 & 746 & 315 & & \multirow{2}{*}{0.49} \\
Overall accuracy & & & & & \\
\hline
\end{tabular}

the south eastern portion of Town Brook on 28-30 April 2006 using a Garmin GPS (GPSmap 60C, Garmin Inc.) with $2 \mathrm{~m}$ horizontal accuracy. Areas were deemed saturated if there were signs of surface saturation or water tables close to the ground surface (e.g. bootprints would fill with water). Manual delineations of HAAs from the field mapping survey of the Town Brook watershed are shown in Fig. 6. The produced map of saturated areas was converted into a raster file with $30 \mathrm{~m} \times 30 \mathrm{~m}$ resolution and classified according to the land cover types derived from the remote sensing data (de Alwis, 2007). This map was compared with the 7 May 2001 NDWI derived image. The area of each specific land cover from the May NDWI image within the survey area was calculated and a ratio of total mapped saturation area to NDWI saturated area was derived, with the corresponding errors of omission and commission calculated (Table 4). Since saturated areas generally occur in the same location from year to year, we expected a general agreement on the location of these saturated areas but not necessarily on the extent of the saturated areas, since measurements taken in 2006, were made under relatively wet conditions and the NDWI values, were taken on 7 May 2001, following two weeks of dry conditions.

Indeed, we found that the general location of the saturated areas were predicted well but the mapped extent agreed less well with an overall accuracy of $49 \%$ (Fig. 6, Table 4). As Table 4 shows, the NDWI predicted a generally larger extent of saturated areas compared to the field survey. Similar to the comparison with the simulation model, the coniferous forest was predicted poorly with low user's accuracies 


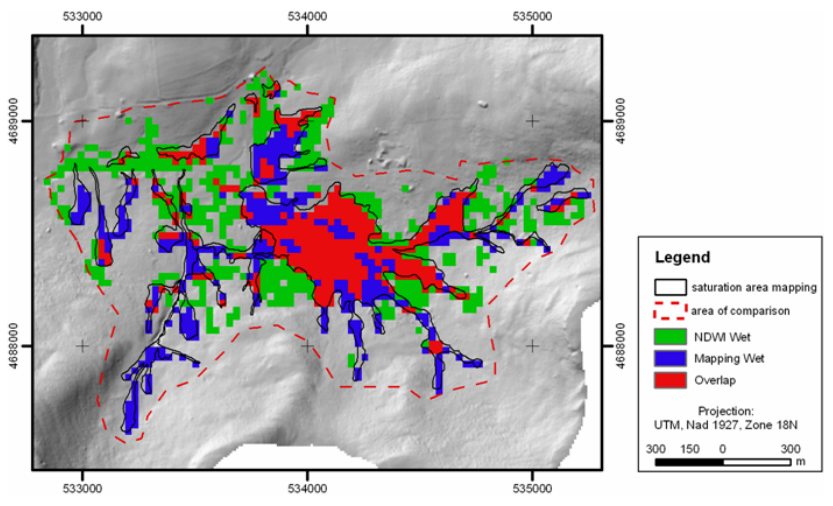

Fig. 6. Field survey delineated saturated areas in a portion of the Town Brook watershed compared to the NDWI predicted saturated area of the 7 May 2001 image.

(Table 4). The correspondence between field observation and NDWI based predictions for land cover classes of deciduous forest and shrub show good agreements with accuracies of $48 \%$ and $71 \%$ respectively. As Fig. 6 illustrates, most of the spatial disagreement between NDWI derived and mapped saturated areas results from an over-prediction of saturation areas in the grass land cover classes and an under-prediction in the deciduous forest and shrub land cover classes. The main discrepancy between the NDWI saturated areas and the mapped saturated area extents occurs in the coniferous forest land cover class, where the NDWI reached the highest (positive) value because of the high LAI. Similar to deciduous forest during the growing season, the leaf water status of the coniferous forest is most likely less affected by short term changes in soil saturation as in other vegetation classes (grass/pasture, shrub, deciduous forest).

\section{Discussion}

In theory, areas within a land cover type situated on a steep slope, deep soils, a high permeability, and a low contributing area should remain drier than those areas with shallow slopes and soils, low permeability, and a large contributing area. In such steep-sloped areas within each landcover type the NDWI is lower during the early spring. The depth of the soil, a proxy for soil storage capacity, directly influences the leaf water content in late summer and during dry periods, while the depth of the soil is inversely proportional to the wetness of the soil in early spring.

Analysis of the NDWI data during a complete phenological cycle within a land cover type highlights significant hydrological characteristics within the land cover. While the NDWI varies proportionally with the surface water content before leaf on (early spring) and leaf water content during leaf on (summer), the largest differences were consistently detected during the spring (Fig. 3), consistent with the other measurements and model analysis from the region. There were few differences detected during the summer and early fall periods, as watersheds in this region tend to dry out during the period from June to October when evapotranspiration is greater than precipitation. However, there were differences in the NDWI for the arable and pasture land covers during the summer. Specifically, the areas with a higher NDWI in the spring had considerably lower values than other areas in the summer (Fig. 3). There are likely numerous explanations for this observation, but several appear more probable. First in these HAAs, the shallow, low storage soils are prone to drying out, providing inadequate plant available water to produce similar biomass as the non-saturation prone areas. Second, and related to the first, the arable and pasture land covers typically have less developed root systems and probe the soil less aggressively for moisture than the forest or shrub type land covers, making them more susceptible to moisture stress. In order to capture HAAs using a NDWI a comparison of images acquired during wet and dry periods during leaf on season (summer) best support the differentiation of soil moisture and leaf water differences among all land cover classes.

The time series of the NDWI images exhibit characteristics consistent with the hydrologic setting of the land covers considered. Interestingly coniferous forest behaved differently than the other land cover types. The region that had high NDWI during the early growing season and low NDWI during the late growing season that was hypothesized as the wet area (HAA) was predicted as dry according to the hydrological models. The high NDWI measured during the spring was clearly not due to the soil surface water content as the satellite would not sense the soil surface as the LAI would be well above six. Another reason could be due to the fact that NDWI responds differently to evergreen needles. Further study needs to be done to explain this atypical behavior among the coniferous forests.

A significant issue in using this approach is the availability of the imagery for a single year. The Landsat 7 ETM+ satellite collects imagery over the study area once every 16 days or about 23 times per year. The maximum amount of data that would be available to create a one-year time series would be 23 images. In practice, getting a sequence of six to eight images that are roughly equally-spaced through the year could be difficult with Landsat 7 ETM+ data. However, the Landsat 7 ETM+ data were selected because its spatial resolution matched the need to identify relatively small regions of uniform land cover classes. Where spatial resolution is not so critical, there are satellite-based instruments (e.g. MODIS with $1 \mathrm{~km}$ pixels and appropriate spectral bands) that provide coverage every one to two days, and should be capable of providing much more detailed time series. However, the resolution is such that delineating saturated areas can be difficult (only 37 pixels for Town Brook). This invites the question of how many images are actually required and what the critical time periods are. It is clear that the April image was imperative to capture the saturated areas in the watershed 
(Fig. 3). It is not clear that both the June and July images were needed as there were only differences detected between classes in the arable land and pasture land covers (Fig. 3). These difficulties aside, it appears that the time-series examined here contain unique and useful information, and that the procedure holds significant promise for hydrologic applications.

It is likely that either or both the Landsat 7 and Landsat 5 satellites could fail after several more years of operation and both satellites will likely run out of fuel before the end of 2010. The Earth observation community is facing a probable gap in Landsat data continuity before the Landsat Data Continuity Mission (LDCM) data arrive in approximately 2011. However, several other sensors can provide promising sources of Landsat-like data, including the China/Brazil Earth Resources Satellite (CBERS-2), and the Indian Remote Sensing (IRS-P6) ResourceSat-1 satellite.

This series analysis of remotely sensed spectral data has never been used for the identification of HAAs but holds great potential, particularly at large scale since the derivation is independent of field measurements and hydrological parameters. However since this study was conducted in a temperate humid region of the country this method is based specifically on vegetation and likely cannot be used to predict saturated areas in semi arid and arid areas, or areas where runoff is generated by infiltration excess processes and not from saturated areas of the landscape. The method might successfully be applied to determine relative differences in moisture contents in many areas, VSA or otherwise. Further work is necessary to investigate application of this method to other regions.

\section{Conclusions}

Based on the temporal pattern of a wetness index derived from remotely sensed satellite imagery we were able to identify HAAs using an unsupervised classification technique. This method is advantageous because it allows identification of HAAs independent of field measurements at a high spatial resolution. The two images in the early and late growing season contributed substantially to the accuracy of the results and were critical in the sequence, since during these periods plant growth is rapid and reflective of the stresses to which they are subjugated. The April image collected when there was four $\mathrm{cm}$ of snow on the ground, and the May image that was taken after 15 days of drought contributed substantially to the analysis. The largest variation among each homogeneous land cover type was seen on the April image with snow cover. The May image showed the NDWI to decrease due to the 15 precipitation free days prior to the image; the increase in NDWI thereafter was due to increases in the leaf water content, particularly for the arable land and pasture land covers.
The derived maps of saturated areas were validated by comparison with two distributed hydrologic models and mapped saturated areas. The results of the validation have shown the remotely sensed data to adequately represent the spatial distribution of saturated areas for most land covers in the watershed. This technique of delineating saturated areas shows promise for many applications requiring knowledge of HAAs, such as hydrologic modeling, landuse planning, zoning, or implementing management practices to reduce pollution.

Edited by: F. Gallart

\section{References}

Beven, K. J.: Rainfall-runoff modeling: the primer, John Wiley \& Sons, LTD, Chichester, England, 360 pp, 2001.

Bindlish, R., Jackson, T. J., Wood, E., Huilin, G., Starks, P., Bosch, D., and Lakshmi, V.: Soil moisture estimates from TRMM Microwave Imager observations over the Southern United States, Remote Sens. Environ., 85, 507-515, 2003.

Ceccato, P., Flasse, S., Tarantola, S., Jacquemoudy, S., and Gr'egoire, J. M.: Detecting vegetation leaf water content using reflectance in the optical domain, Remote Sens. Environ., 77, 22 33, 2001.

Chen, J. M. and Cihlar, J.: Retrieving leaf area index of boreal conifer forests using LANDSAT TM images, Remote Sens. Environ., 55, 153-162, 1996.

Cohen, W. B., Maiersperger, T. K., Gower, S. T., and Turner, D. P.: An improved strategy for regression of biophysical variables and LANDSAT ETM+ data, Remote Sens. Environ., 84, 561-571, 2003.

de Alwis, D. A.: Identification of hydrologically active areas in the landscape using satellite imagery, PhD Dissertation, Cornell University, Ithaca, NY, 2007.

De Jong, R., Shields, J. A., and Sly, W. K.: Estimated soil water reserves applicable to a wheat-fallow rotation for generalized soil areas mapped in southern Saskatchewan, Canadian J. Soil Sci., 64(3), 667-680, 1984.

Dunne, T. and Black, R. D.: Partial area contributions to storm runoff in a small New England watershed, Water Resour. Res. 6, 1296-1311, 1970.

Dunne, T. and Leopold, L: Water in Environmental Planning, W. H. Freeman \& Co., New York. 818 pp, 1978.

Easton, Z. M., Gérard-Marchant, P., Walter, M. T., Petrovic, A. M., and Steenhuis, T. S.: Hydrologic assessment of an urban variable source watershed in the northeast United States, Water Resour. Res., 43, W03413, doi:10.1029/2006WR005076, 2007.

Farrar, T. J., Nicholson, S. E., and Lare, A. R.: The influence of soil type on the relationships between NDVI, rainfall, and soil moisture in semiarid Botswana, Remote Sens. Environ., 50(2), 121-133, 1994.

Fassnacht, K. S., Gower, S. T., MacKenzie, M. D., Nordheim, E. V., and Lillesand, T. M.: Estimating the leaf area index of north central Wisconsin forests using the LANDSAT Thematic Mapper, Remote Sens. Environ., 61, 229-245, 1997.

Fensholt, R.: Earth observation of vegetation status in the Sahelian and Sudanian West Africa, comparison of Terra MODIS and NOAA AVHRR satellite data, Int. J. Remote Sens., 25(9), 16411659, 2004. 
Foody, G. M. and Arora, M. K: Incorporating mixed pixels in the training, allocation and testing stages of supervised classifications, Pattern Recognition Lett., 17, 1389-1398, 1996.

Frankenberger, J. R., Brooks, E. S., Walter, M. T., Walter, M. F., and Steenhuis, T. S.: A GIS based variable source area hydrology model, Hydrol. Processes, 13, 805-822, 1999.

Friedl, M. A., Michaelsen, J., Davis, F. W., Walker, H., and Schimel, D. S.: Estimating grassland biomass and leaf area index using ground and satellite data, Int. J. Remote Sens., 15, 1401-1420, 1994.

Gao, B.: NDWI. A normalized difference water index for remote sensing of vegetation liquid water from space, Remote Sens. Environ., 58(3), 257-266, 1996.

Gates, D., Keegan, J. J., Schleter, J. C., and Weidner, V. R.: Spectral properties of plants, Appl. Optics, 4, 11-20, 1965.

Guha, A. and Lakshmi, L.: Sensitivity, spatial heterogeneity, and scaling of C-Band microwave brightness temperatures for land hydrology studies, IEEE Trans. Geosci. Remote Sensing, 40(12), 2626-2635, 2002.

Haith, D. A. and Shoemaker, L. L.: Generalized Watershed Loading Functions for stream flow nutrients, Water Resour. Bull., 23(3), 471-478, 1987.

Hively, W. D., Gerard-Marchant, P., and Steenhuis, T. S.: Distributed hydrological modeling of total dissolved phosphorus transport in an agricultural landscape, part II, dissolved phosphorus transport, Hydrol. Earth Syst. Sci., 10, 263-276, 2006, http://www.hydrol-earth-syst-sci.net/10/263/2006/.

Hunt Jr., E. R., Rock, B. N., and Nobel, P. S.: Measurement of leaf relative water content by infrared reflectance, Remote Sens. Environ., 22, 429-435, 1987.

Karnieli, A., Kaufman, Y., Remer, L., and Wald, A.: AFRI aerosol free vegetation index, Remote Sens. Environ., 77(1), 1021, 2001.

Kerr, Y. H.: Soil moisture from space: Where are we?, Hydrogeology J., 15, 117-120, 2007.

Killelea, M.: Carbon storage in New York State forestland, Ph.D. Dissertation, Cornell University, Ithaca, NY, USA, 2005.

Law, B. E. and Waring, R. H.: Remote sensing of leaf area index and radiation intercepted by understory vegetation, Ecol. Apps., 4, 272-279, 1994.

Le Hegarat-Mascle, S., Bloch, I., and Vidal-Madjar, D.: Application of Dempster-Shafer evidence theory to unsupervised classification in multisource remote sensing, IEEE Trans. Remote Sens., 35, 1018-1031, 1997.

Lu, D., Mausel, P., Brondizio, E., and Moran, E.: Assessment of atmospheric correction methods for Landsat TM data applicable to Amazon basin LBA research, Int. J. Remote Sens., 23, 26512671, 2002.

Lyon, S. W., Walter, M. T., Gerard-Marchant, P., and Steenhuis, T. S.: Using a topographic index to distribute variable source area runoff predicted with the SCS curve-number equation, Hydrol. Processes, 18, 2757-2771, 2004.

Mehta, V. K., Walter, M. T., Brooks, E. S., Steenhuis, T. S., Walter, M. F., Johnson, M., Boll, J., and Thongs, D.: Application of SMR to modeling watersheds in the Catskill Mountains, Environ, Model. Assess., 9, 77-89, 2004.

Needelman, B. A., Gburek, W. J., Petersen, G. W., Sharpley, A. N., and Kleinman, P. J. A.: Surface runoff along two agricultural hillslopes with contrasting soils, Soil Sci. Soc. Am. J., 68, 914-
923, 2004.

Nicholson, S. E. and Farrar, T. J.: The influence of soil type on the relationships between NDVI, rainfall, and soil moisture in semiarid Botswana, Remote Sens. Environ., 50, 107-120, 1994.

Research Systems, Inc. ENVI Users Manual, What's new in ENVI 4.0 ENVI Version 4 Edition, Boulder, Colorado, 2002.

Richardson, A. J., Wiegand, C. L., Wanjura, D. F., Dusek, D., and Steiner, J. L.: Multisite analyses of spectral-biophysical data for Sorghum, Remote Sens. Environ., 41(1), 71-82, 1992.

Schmugge, T.: Remote sensing of soil moisture, in: Hydrological Forecasting, edited by: Anderson, M. G. and Burt, T. P., Wiley, New York, 101-124, 1985.

Schneiderman, E. M., Steenhuis, T. S., Thongs, D. J., Easton, Z. M., Zion, M. S., Mendoza, G. F., Walter, M. T., and Neal, A. L.: Incorporating variable source area hydrology into the curve number based Generalized Watershed Loading Function model, Hydrol. Processes, in press, available online at: http://www3. interscience.wiley.com/cgi-bin/jissue/89013836, 2007.

Song, C., Woodcock, C. E., Seto, K. C., Pax-Lenney, M., and Macomber, S. A.: Classification and change detection using Landsat TM data: when and how to correct for atmospheric effects, Remote Sens. Environ., 75(2), 230-244, 2001.

Timlin, D. J., Pachepsky, Y., Walthall, C. L., and Loechel, S. E.: The use of a water-budget model and yield maps to characterize water availability in a landscape, Soil and Tillage, 58, 219-231, 2001.

Tou, J. T. and Gonzalez, R. C.: Recognition of handwritten characters by topological Feature extraction and multilevel categorization, IEEE Trans. Computers, 21, 776-787, 1972.

Tucker, C. J.: Remote sensing of leaf water content in the near infrared, Remote Sens. Environ., 10, 23-32, 1980.

USDA-SCS (Soil Conservation Service): National Engineering Handbook, Part 630 Hydrology, Section 4, Chapter 10, 1972.

Viovy, N.: Automatic Classification of Time Series (ACTS): a new clustering method for remote sensing time series, Int. J. Remote Sens., 21, 1537-1560, 2000.

Wagner, W., Naeimi, V., Scipal, K., de Jeu, R., and MartinezFernandez, J.: Soil moisture from operational meteorological satellites, Hydrogeology J., 15, 121-131, 2007.

Wang, J. R. and Schmugge, T. J.: An empirical model for the complex dielectric permittivity of soils as a function of water content, IEEE Trans. Geosci. Remote Sens., 18(4), 288-295, 1980.

Wang, J., Price, K. P., and Rich, P. M.: Spatial patterns of NDVI in response to precipitation and temperature in the central Great Plains, International J. Remote Sens., 22(18), 3827-3844, 2001.

Whiting, M. L., Lin, L., and Ustin, S. L.: Predicting water content using Gaussian model on soil spectra, Remote Sens. Environ., 89(4), 535-552, 2004.

Xiao, X., Boles, S., Liu, J. Y., Zhuang, D. F., and Liu, M. L.: Characterization of forest types in Northeastern China, using multitemporal SPOT-4 VEGETATION sensor data, Remote Sens. Environ., 82, 335-348, 2002.

Yang, J. P., Ding, Y. J., and Chen, R. S.: Spatial and temporal of variations of alpine vegetation cover in the source regions of the Yangtze and Yellow Rivers of the Tibetan Plateau from 1982 to 2001, Environ. Geol., 50(3), 313-322, 2006.

Zollweg, J. A., Gburek, W. J., and Steenhuis, T. S.: SMoRModA GIS-integrated rainfall-runoff model applied to a small northeast U.S. watershed, Trans. ASAE, 39, 1299-1307, 1996. 